\title{
ORGANIZED DIFFERENTIATION OF TUMOR CELLS OF VILLOUS ADENOMAS OF THE LARGE INTESTINE
}

\author{
Hiroyoshi OTA ${ }^{1}$, Jun NAKAYAMA ${ }^{1}$, Yoshifumi FUJIMORI ${ }^{1}$, Ken-IGHI FURIHATA $^{1}$, \\ Tsutomu KATSUYAMA ${ }^{1}$, SHIN-ICHI MORIYAMA ${ }^{2}$, \\ SAtoru HATA ${ }^{2}$ AND Kenzo $\mathrm{ONO}^{3}$
}

Department of Laboratory Medicine ${ }^{1}$, Shinshu University School of Medicine, Matsumoto 390, Devision of Central Clinical Laboratories ${ }^{2}$, Nagano Red Cross Hospital, Nagano 380 and Devision of Pathology ${ }^{3}$, Tosei Hospital, Seto 489

Received for publication April 24, 1992 and in revised form September 17, 1992

\begin{abstract}
The present study was undertaken to explore whether tumor cells of villous adenomas of the human colon showed an organized expression of differentiation markers. Eleven cases of villous adenomas were examined by employing histochemical techniques, which are useful for characterizing the colonic mucosa, including high iron diamine-alcian blue pH 2.5, lectin stains with DBA, GSA-I and UEA-I, immunostainings for blood group A determinant, lysozyme, and proliferating cell nuclear antigen (PCNA). The results demonstrated that the adenoma tissues showed the organized expression of these sugar moieties or antigens similar to those found in the normal colon crypts. Namely, tumor cells in the upper portions of tumor tissues revealed characteristic features of normal epithelia, lining the upper compartment of the crypts, and contained sialomucins, which possessed DBA reactivity. Tumor cells in the lower portions, on the other hand, resembled epithelia lining the lower compartments of the crypts, contained sulfomucins, showed GSA-I and UEA-I reactivities, and stained for blood group A determinant and lysozyme. PCNA-positive cells were more abundant in the lower portions of the tumor tissues than in the upper portions. It seems likely that cellular differentiation, similar to normal crypt cells, occurs in the tumor tissues.
\end{abstract}

Carcinoma cells have been known to differentiate into organized structures, which simulate the cellular differentiation occurring in non-neoplastic tissues $(1$, $11,12,17)$; we have called this phenomenon organized differentiation. Employing histochemical techniques to characterize mucosubstances, the authors have demonstrated "organized differentiation" of tumor cells in adenocarcinoma of the human stomach $(1,12)$ and human pancreas (17). In colonic adenomas, Ota et al. observed findings suggesting the presence of the organized differentiation in the villous adenoma, but not in the tubular adenoma (23). In this study, by employing a battery of histochemical techniques, which are useful to characterize the normal colonic mucosa $(11,21)$, villous adenomas were investigated for the expression of differentiation markers of the normal colonic crypt cells. We found an organized ex-

Correspondence to Dr. Hiroyoshi Ota: Department of Laboratory Medicine, Shinshu University School of Medicine, 3-1-1 Asahi, Matsumoto 390, Japan. pression of those markers in villous adenomas similar to that found in the normal crypt cells. This organized differentiation was closely related with cellular kinetics.

\section{MATERIALS AND METHODS}

Preparation of tissues. Eleven lesions from eleven patients were selected from the pathology files of the Shinshu University Hospital, Nagano Red Cross Hospital, and Tosei Hospital. Nine lesions were surgically removed and the other two were obtained by polypectomy. Following WHO's histological typing of intestinal tumours (20), two lesions were classified as villous adenoma and the other 9 lesions as tubulovillous adenoma. All materials were obtained from the left colon (21). Blood groups of these materials were; 2 cases of $A, 1$ of $B, 1$ of $A B$, and 7 of O.

All specimens were fixed in a $4 \%$ paraformaldehyde solution, buffered with $0.1 \mathrm{M}$ phosphate 
buffer ( $\mathrm{pH} 7.4$ for $24 \mathrm{hr}$ at room temperature), dehydrated through graded alcohol, cleared in xylene and embedded in paraffin. Among various fixatives, which have been recommended for immunostaining with anti-proliferating cell nuclear antigen (PCNA) antibody $(5,24,30)$, a buffered $4 \%$ paraformaldehyde solution was used to retain morphological architecture and antigenicities of PCNA and lysozyme.

Histochemistry. Serial sections of $3 \mu \mathrm{m}$ thickness were cut, baked at $40^{\circ} \mathrm{C}$ for $10 \mathrm{~min}$ on to poly-L-lysine coated glass slides (Muto, Tokyo, Japan) to prevent reducing the intensity of PCNA immunoreactivity, and stained by the following sequences: high iron diamine-alcian blue pH 2.5 (HID-AB) (26), lectin stains, including Dolichos biflorus agglutinin (DBA), Griffonia simplicifolia agglutinin-I (GSA-I), and Ulex europeus agglutinin-I (UEA-I), and immunoperoxidase stains for lysozyme, blood group A determinant and PCNA. The lectin-peroxidase staining followed the method described previously (12). For the immunoperoxidase stain, the streptavidin-biotin complex peroxidase method was employed (2). The dilution rates and sources of reagents are listed in table 1. The lectin-peroxidase stain with GSA-I, and the immunoperoxidase stain for blood group A determinant were applied only after neuraminidase digestion (11, 21 ). To compare the distribution of lysozyme and goblet cells, tissue sections were first stained with the immunoperoxidase method and subsequently with alcian blue $\mathrm{pH} 2.5$.

Significance of stains employed (Table 2). We chose HID$\mathrm{AB}$, the lectin stains, and the immunostaining for the blood group A determinant, because sugar moieties differed consistently among different compartments of normal colorectal crypts $(11,21,22)$. Thus, in the left colon, sialomucin-containing goblet cells occur in the upper crypts, whereas sulfomucincontaining ones are found in the lower crypts (22). DBA binds selectively to goblet cells lining the upper portions of the crypts, and neuraminidase-induced reactivities for GSA-I and anti-blood group A determinant antibody are restricted to those goblet cells lining the lower crypts $(11,21)$. UEA-I shows an affinity to the surface coat lining the deep crypt (11). The immunostain for lysozyme was selected because this antigen occurs in the Paneth cells, which are found at base of the crypts of the small intestine, or occasionally in the colonic adenoma $(6,8,14,15,27)$. For the cell kinetic study, the immunostaining for PCNA was employed. PCNA is a coenzyme of DNA polymerase $\delta$, and its demonstration in nuclei reflects recent or on-going DNA synthesis $(3,13,18)$.

In the villous adenoma tissue, the area was considered to show organized differentiation, if those sugar moieties or lysozyme, except for PCNA, were detected in the same crypt distribution, as in the normal mucosa.

Histochemically detectable organized differentiation was evaluated depending on the relative areas showing organized differentiation, compared with whole areas of tumor tissues; none, up to $1 / 3,1 / 3$ to $2 / 3$ and over $2 / 3$.

The proportions of PCNA-positive cells were quantitatively assessed. The entire height of normal mucosa and adenoma tissues were divided into three horizontal zones with equal breadth. Non-neoplastic mucosa of each tissue preparation was used as the control. In normal mucosa, 10 longitudinally oriented

TABLE 1. Dilution rates of reagents and their sources

\begin{tabular}{lll}
\hline \multicolumn{1}{c}{ Reagent } & Dilution rate & \multicolumn{1}{c}{ Source } \\
\hline Dolichos biflorus agglutinin & $1: 100$ & E. Y. $^{\mathrm{a}}$ \\
Griffonia simplicifolia agglutinin-I & $1: 50$ & E. Y. \\
Ulex europeus agglutinin-I & $1: 30$ & E. Y. \\
Anti human lysozyme & $1: 500$ & DAKO $^{\mathrm{b}}$ \\
Anti blood group A & $1: 50$ & DAKO \\
Anti proliferating cell nuclear antigen & $1: 50$ & DAKO \\
Biotinylated anti rabbit antibody & $1: 200$ & DAKO \\
Biotinylated anti mouse anibody & $1: 200$ & DAKO \\
Peroxidase-labeled streptavidin & $1: 100$ & DAKO \\
Biotin Complex & & \\
\hline
\end{tabular}

Abbreviation used in this table

a E. Y. Laboratories, San Mateo, CA, U.S.A.

b DAKOPATTS, Glostrup, Denmark 
TABLE 2. Significance of the histochemical stains

\begin{tabular}{llll}
\hline & $\begin{array}{l}\text { Chemical groups } \\
\text { or antigens detected }\end{array}$ & Cell species & $\begin{array}{l}\text { Distribution } \\
\text { in normal crypt }\end{array}$ \\
\hline HID-AB & Sulfomucin (HID) & Loblet cell & Lompartment \\
& Sialomucin (AB) & Upper compartment \\
Lectins & $\alpha$-GalNAc & Goblet cell & Upper compartment \\
DBA & $\beta$-GalNAc or $\alpha$-Gal & Goblet cell & Upper compartment \\
NANAase-GSA-I & $\alpha$-Fuc & Columnar cell & Lower compartment \\
UEA-I** & & & \\
Immunostains & GalNAc $\alpha-(\alpha$-Fuc) $\beta$-Gal & Goblet cell & Lower compartment \\
NANAase-Blood & Paneth cell & Lower compartment \\
group A determinant & (Small intestine) \\
Lysozyme & Lysozyme & Any cell species & Lower compartment \\
PGNA & PCNA & &
\end{tabular}

Abbreviation used in this table

NANAase: neuraminidase, GalNAc: N-acetylgalactosamine, Fuc: fucose, Gal: galactose

For other abbreviations appearing in this table, see text.

* The sialomucin-sulfomucin gradient in the crypts are observed in the left colon.

** The UEA-I reactivity confined to the apical surface of the columnar cells lining the lower crypts of the left colon. This gradient is not evident in the right colon.

*** Blood group A reactivity confined to the goblet cells lining the lower crypts in materials obtained from patients other than blood group A.

crypts were selected for the analyses. Then the numbers of nuclei of all epithelial cells and PCNApositive nuclei were counted in each compartment. In adenoma tissues, 1000 cells were counted in each zone, and the ratio of PCNA-positive cells was calculated in the area with or without showing organized differentiation respectively. Statistical significance was evaluated using one-way analysis of the variance (one-way ANOVA).

\section{RESULTS}

Tumor cells, either of goblet cell-type or columnar cell-type, varied extensively in their histochemical reactivities. Goblet cell-type tumor cells were the predominant type among neoplastic cells (Fig. 1a). In this paper, only findings related to organized differentiation were described in detail.

Relative areas showing organized differentiation in adenoma tissues were summarized in Table 3.

DBA: In 9 of 11 cases, neoplastic goblet cells in the upper portions of adenoma tissues showed more intense DBA reactivity than those in the lower portions (Fig. 1b). In other cases, neoplastic goblet cells revealed DBA reactivities, regardless of the location in the adenoma tissues.

Neuraminidase-GSA-I: In 10 of 11 cases, neoplastic goblet cells in the lower portions of the adenoma tissues showed intense reactivity. The organized differentiation was most evident by this stain (Fig. 1c). UEA-I: In 7 of 11 cases, the apical surface of adenoma cells, in the lower portions of tumor tissues, showed UEA-I reactivity (Figs. 2a, b).

HID-AB: In eight cases, neoplastic goblet cells were stained for sialomucin in the upper portions of the adenoma tissues, and for sulfomucin in the lower portions (Figs. 3a, b). In other cases, both types of the acid mucins occurred irregularly in neoplastic goblet cells.

Neuraminidase-anti-A antibody: In materials obtained from blood group A patients, neoplastic goblet cells and the surface coat consistently showed blood group A reactivity, and therefore were excluded from the evaluation. In 3 of 9 cases obtained from patients other than blood group A, the neuraminidaseengendered antigenicity was demonstrated in neoplastic goblet cells in the lower portions of the adenoma tissues (Fig. 4).

Lysozyme-alcian blue $\mathrm{pH}$ 2.5: Lysozyme was demonstrated in the tumor cells lining the lower portions of the adenoma tissues in 6 of 11 cases (Figs. 5a, b). Immunoreactivity was mostly restricted to the apical cytoplasm of the tumor cells, and a portion of the positive cells were obviously neoplastic goblet cells (Fig. 5b). The comparison with the preparations stained with hematoxylin-eosin revealed that lysozyme 


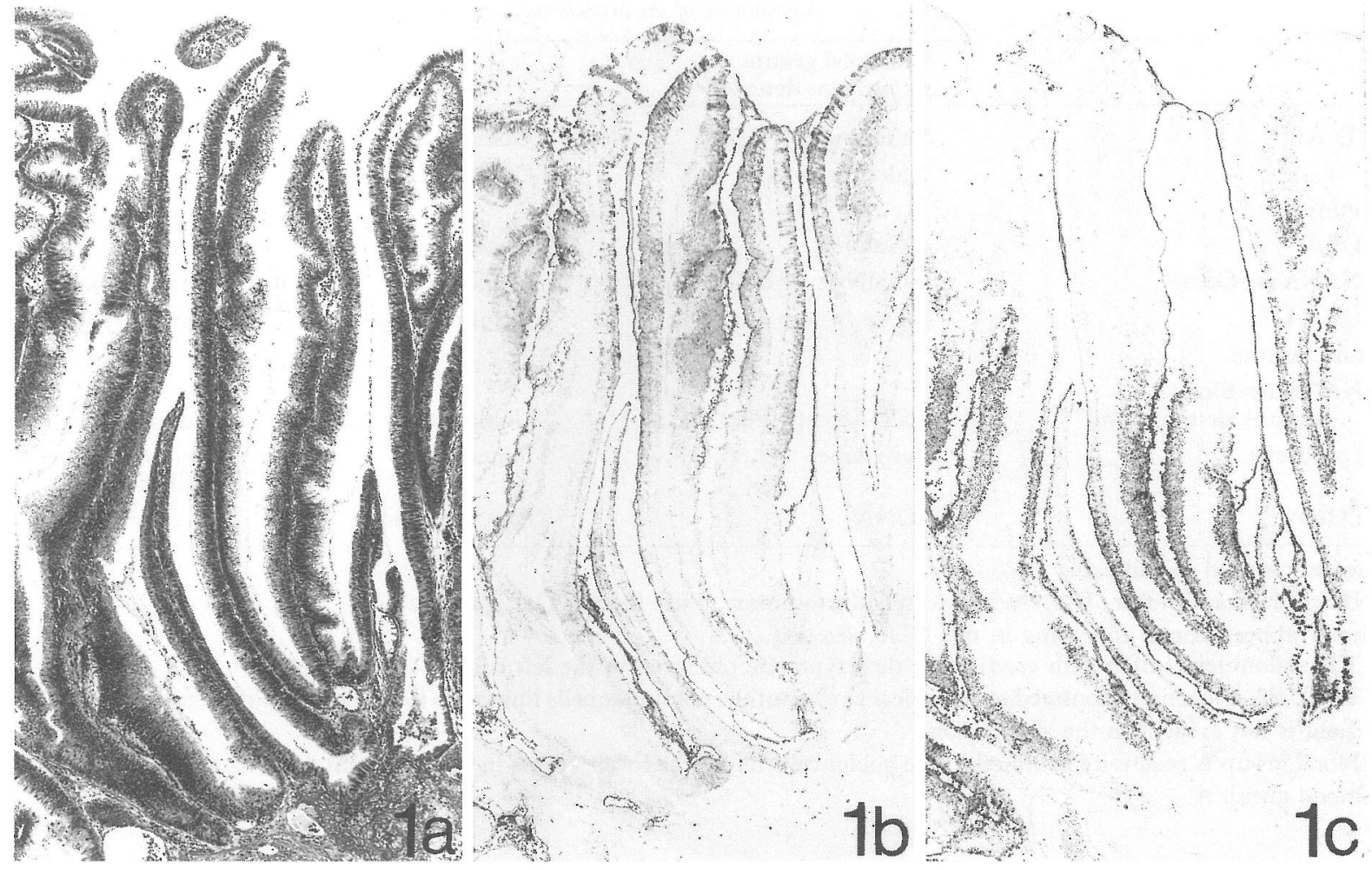

Figs. 1a to $1 \mathrm{c}$ were prepared from serial sections.

FIG. 1a. Neoplastic goblet cells are predominant among adenoma cells. Hematoxylin and Eosin. $\times 50$

FIG. 1b. Neoplastic cells in the upper portion show more intense reactivity than those lining the lower portion. Dolichos biflorus agglutinin-peroxidase stain. $\times 50$

FIG. 1c. Neoplastic cells in the lower portion show more intense reactivity than those in the upper portion. Neuraminidase-Griffonia simplicifolia agglutinin-I-peroxidase stain. $\quad \times 50$

reactive sites appeared minutely granular and eosinophilic, and differed from Paneth cells, in lacking typical large eosinophilic granules, as well as in the location of reactive sites (Figs. 5, 6).

Among the tumor tissues examined, the organized expression of 4 markers was observed in 5 cases. In other cases, markers which disclosed the organized expression were less than 4 (Table 4 ).
PCNA: The PCNA stain showed a diffuse or granular nuclear staining pattern and a gradual decrease in staining intensity, from lower to upper compartments of the crypts in normal mucosa (Fig. 7) and in the adenoma tissues (Fig. 8). Although the degree of the intensity of the nuclear immunoreactivity varied extensively, all reactive nuclei, irrespective of intensity, were scored as positive.

TABLE 3. Organized differentiation in adenoma tissues detected by different methods

\begin{tabular}{ccccccc}
\hline & DBA & $\begin{array}{l}\text { NANAase } \\
\text { GSA-I }\end{array}$ & UEA-I & HID-AB & $\begin{array}{c}\text { NANAase } \\
\text { anti-A }\end{array}$ & Lysozyme \\
\hline up to $1 / 3$ & 4 & 2 & 1 & 2 & 3 & 1 \\
$1 / 3-2 / 3$ & 1 & 2 & 6 & 2 & 0 & 5 \\
over $2 / 3$ & 4 & 6 & 0 & 4 & 0 & 0
\end{tabular}

For abbreviations appearing in this table, see Table 1.

Fractions on the left column mean that relative areas of adenoma tissues showed organized differentiation. The numerals in each column indicate the number of cases showing organized differentiation. 


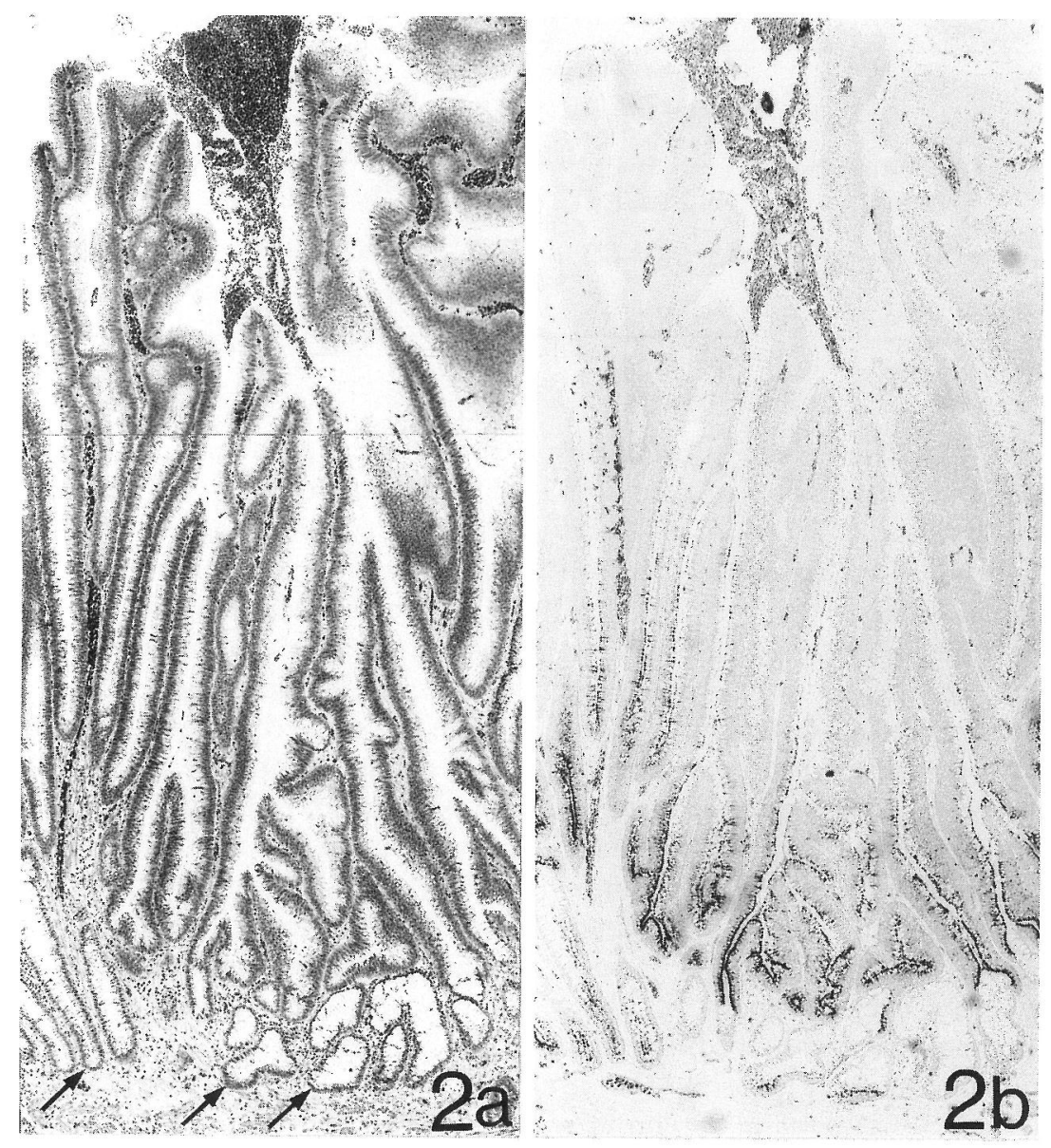

Figs. $2 \mathrm{a}$ and $2 \mathrm{~b}$ were prepared from serial sections.

FIG. 2a. Neoplastic goblet cells also are predominant among adenoma cells. At the bottom of the tumor tissue, normal colonic crypts remain (arrows). Hematoxylin and eosin. $\quad \times 20$

Fig. 2b. Neoplastic cells lining the lower portion show an intense reactivity on their apical surface. Ulex europeaus agglutinin-Iperoxidase stain. $\quad \times 20$

The proportion of positive nuclei in each compartment of normal mucosa differed among three sites; in the upper compartment the proportion was $33.9 \% \pm 7.2 \mathrm{SEM}$, in the middle it was $58.7 \% \pm 7.9$, and in the lower it was $70.5 \% \pm 7.2$. These figures were statistically different $(F>.005)$ (Table 5$)$. In the adenoma tissues, the proportion of labeled nuclei in tumor tissues, showing organized differentiation, was $20.7 \% \pm 7.3$ in the upper, $38.7 \% \pm 8.3$ in the middle,

TABLE 4. Number of positive markers in tumor tissues showing organized differentiation in each case

\begin{tabular}{llllllll}
$\begin{array}{l}\text { Number of } \\
\text { Markers }\end{array}$ & 0 & 1 & 2 & 3 & 4 & 5 & 6 \\
Cases & 0 & 0 & 3 & 3 & 5 & 0 & 0 \\
\hline
\end{tabular}

and $43.1 \% \pm 9.3$ in the lower, and the difference was statistically significant $(F>.005)$ (Table 5). In the tumor tissues lacking organized differentiation, the figures were $46.9 \% \pm 8.6$ in the upper, $52.4 \% \pm 8.7$ in the middle, and $50.9 \% \pm 7.7$ in the lower respectively, and the difference was not statistically significant $(\mathrm{F}<.005)$ (Table 5).

\section{DISCUSSION}

The present study confirmed the previous report, which suggested the presence of the organoid differentiation of tumor cells in villous adenoma of the large intestine (23), and further demonstrated the organized expression of various sugar moieties and lysozyme in this type of colonic adenoma. Among these moieties or antigens, mucosubstances, reactive to GSA-I after 
TABLE 5. Relation between PCNA-labeling indices and organized differentiation

\begin{tabular}{ccccc}
\hline & & & \multicolumn{2}{c}{$\begin{array}{c}\text { Adenoma tissue } \\
\text { Organized differentiation }\end{array}$} \\
\cline { 3 - 5 } & & & Present & Absent \\
\hline Upper & layer & $33.9 \% \pm 7.2$ & $20.7 \% \pm 7.3$ & $46.9 \% \pm 8.6$ \\
Middle layer & $58.7 \% \pm 7.9$ & $38.7 \% \pm 8.3$ & $52.4 \% \pm 8.7$ \\
Lower & layer & $70.5 \% \pm 7.2$ & $43.1 \% \pm 9.3$ & $50.9 \% \pm 7.7$ \\
\hline
\end{tabular}

neuraminidase digestion, most frequently showed the gradient with increased lower expression in adenoma tissues, whereas the organized expression of blood group A determinant, exposed by the same pretreatment, appeared only occasionally.

It is well known that various substances, including mucosubstances, are present in epithelial cells lining different compartments of the colonic crypts $(11,12,21,22,25)$. Most of these represent normal differentiation antigens or, at least, are expressed as the maturation of the lining cells. Since the organized distribution of various moieties or antigens examined in this study resembled their occurrence in the crypt of the normal mucosa $(11,12,21,22)$, the therm "organized" could be replaced by "organoid". This organoid expression in adenoma tissues is comparable with that of different mucins and pepsinogens in gastric $(1,12,29)$, as well as pancreatic carcinomas (17).

The similar gradient in the colonic adenoma tissues has been reported by two different groups $(10$, 25). However, they did not refer to the relative areas showing the gradient.

Ruggiero et al. (25) examined the distribution of various sugar moieties in the normal, as well as neoplastic tissues, in the large intestine. Among antigens examined, sialosyl-Le $\mathrm{L}^{\mathrm{a}}$ and $\mathrm{Le}^{\mathrm{y}}$ were markers for undifferentiated crypt base epithelium, and when presented in adenomas, they were frequently expressed in the same compartment of the crypt as in the normal colon. Since the UEA-I used in this study most possibly binds to $\mathrm{Le}^{\mathrm{y}}$ in the colon mucosa (23), the reactivity for this lectin of the adenoma tissues corresponded well with Ruggiero's findings. Iwashita et al. (10), on the other hand, reported that argyrophil or argentaffin cells tended to be distributed in the deeper layer of the neoplastic tubules of adenoma tissues, as in normal crypts.

In the present study, in addition to the typical neoplastic Paneth cells, neoplastic cells, containing both mucins and lysozyme, were found in the basal regions of the tumors. Intestinal epithelial cells, producing both lysozyme and mucosubstances in the human small intestine, were first described by

FIG. 3a. Neoplastic goblet cells contain sialomucin in the upper portion and sulfomucin in the lower portion. High iron diaminealcian blue $\mathrm{pH} 2.5$ stain. $\quad \times 13$

Fig. 3b. Higher magnification of the basal region of several crypts in the Fig. 3a. Neoplastic goblet cells in the lower portion obviously contain sulfomucin. High iron diamine-Alcian blue pH 2.5 stain. $\times 35$

FIG. 4. Neoplastic cells in the lower portion contain blood group A determinant (arrows). The immunostain for blood group A determinant after neuraminidase digestion. $\times 35$ Inset: At higher magnification, neoplastic goblet cells obviously contain blood group A determinant. $\times 345$

Figs. 5 and 6 were prepared from serial sections and represent the basal portion of the villous adenoma.

Fig. 5a. Immunoreactive cells locate in the lower portions, whereas neoplastic goblet cells distribute throughout the tumor tissue and contain sulfomucins almost exclusively. Anti-lysozyme immunoperoxidase-alcian blue $\mathrm{pH} 2.5$ staining. $\quad \times 113$

FIG. 5b. At higher magnification, some neoplastic cells contain lysozyme and mucins in the apical cytoplasm (arrows). Nuclear staining is thought to be artifactual products caused by diffusion during fixation. Anti-lysozyme-alcian blue $\mathrm{pH} 2.5$ staining. $\times 452$

Fig. 6a. Neoplastic goblet cells predominate even in the basal portion. Hematoxylin and eosin staining. $\times 113$

FIG. 6b. At higher magnification, some neoplastic goblet cells contain eosinophilic granules. Hematoxylin and eosin staining. $\times 452$

Fig. 7. Normal colonic mucosa. PCNA reactivity gradually decreases in staining intensity from the lower to upper compartments of the crypts. Anti-PCNA immunostaining. $\times 171$ Inset: At higher magnification, the PCNA is detected in nuclei. $\times 343$

FIG. 8. Villous adenoma of the colon. PGNA-reactive nuclei distribute mainly in the lower portion. Anti-PCNA immunoperoxidase. $\times 34$ Inset: At higher magnification, the PCNA immunoreactivity is localized in nuclei. $\times 343$ 

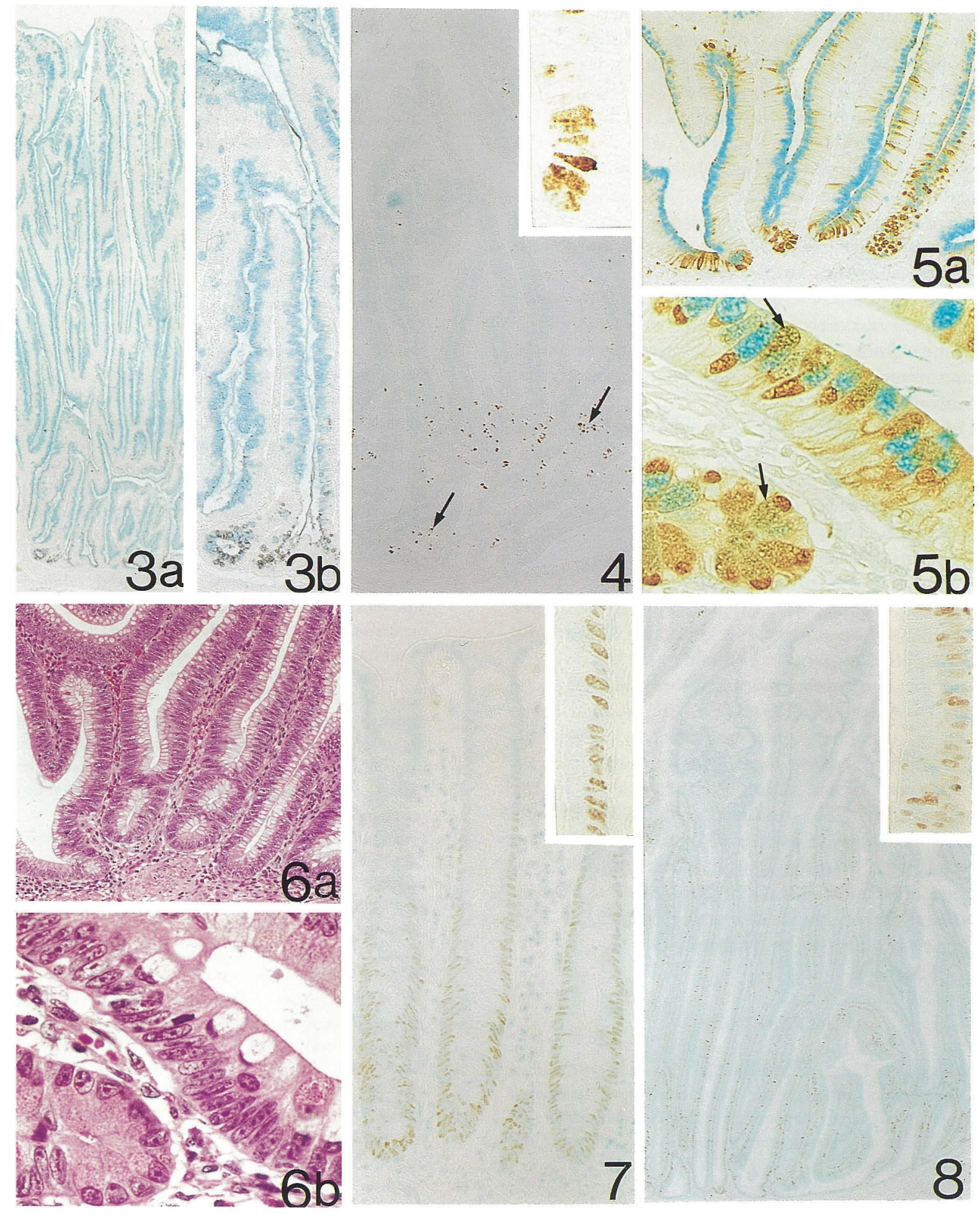
Montero and Erlandsen (19) at the basal region of the crypt, and their report was confirmed by Mathan et al. (16). The occurrence of neoplastic Paneth-goblet cell hybrids in the basal regions of tumor tissues, therefore, seems to represent the organoid differentiation of villous adenoma. Neoplastic Paneth cells have been also detected in the colon tumors, but little attention was paid to their distribution $(6,8,14,15,27)$, except for a report by Lewin et al. (14), who described a case of villous adenoma with neoplastic Paneth cells at the basal region of the tumor tissue. The combination of immunohistochemistry for detecting lysozyme and mucin histochemistry is useful for analyzing the cell differentiation of colonic tumor cells.

The present study suggested that the organoid expression of various moieties and antigens is closely linked with the cellular regeneration and maturation in the adenoma tissues, which were well documented by the distribution of PCNA.

The crypt gradient of PCNA coincided with that of other tissue markers examined in this study. PCNA has been known as an auxiliary nuclear protein of DNA polymerase $\delta$, which appears in nuclei associated with cell cycle $(3,13,18)$. This antigen is detected immunohistochemically in cells with a peak staining intensity at early S-phase, and very low or undetectable staining in M-phase, and in early G1 (13). Recently, an anti-PCNA monoclonal antibody has been applied to paraffin embedded materials (5, 7, 24 ), and its immunoreactivity has been shown to be associated with cell proliferation in the human colon (7). The results obtained with PCNA in the present study, therefore, suggest a cytodifferentiation process from the base of the crypts to the surface in the adenoma tissues. The results obtained with PCNA, however, appeared contrary to those obtained by mitotic indices. Namely, mitotic indices of the villous adenomas are almost consistent throughout the tumor tissues, or slightly higher in the upper layer (31). This discrepancy remains to be clarified.

\section{REFERENCES}

1. Akamatsu, T. and Katsuyama, T.: Histochemical demonstration of mucins in the intramucosal laminated structure of human gastric signet ring cell carcinoma and its relation to submucosal invasion. Histochem. J. 22; 416-425, 1990.

2. Bonnard, C., Papermaster, D. S. and Kraehenbuhl, J. P.: The streptavidin-biotin bridge technique: application in light and electron microscope immunocytochemistry. In "Immunolabelling for Electron Microscopy", chapter 8, ed. by Polak J. M. and Varndell
I. M. Elsevier Scientific Publishers, Amsterdam, 1984, pp. 95-111.

3. Bravo, R., Frank, R., Blundell, P. A. and MacDonaldBravo, H.: Gyclin/PCNA is the auxiliary protein of DNA polymerase delta. Nature 326; 515-517, 1987.

4. Enblad, P., Busch, C., Carlsson, U., Ekelund, G., Glimelius, B., Lindström, C., Pontén, J. and Pahlman, L.: The adenoma-carcinoma sequence in rectal adenomas. Support by the expression of blood group substances and carcinoma antigens. Am. J. Clin. Pathol. 90; 121-130, 1988.

5. Garcia, R. L., Coltrera, M. D. and Gown, A. M.: Analysis of proliferative grade using anti-PCNA/cyclin monoclonal natibodies in fixed, embedded tissues. $\mathrm{Am}$. J. Pathol. 134; 733-739, 1989.

6. Gibbs, N. M.: Incidence and significance of argentaffin and Paneth cells in some tumours of the large intestine. J. Clin. Pathol. 20; 826-831, 1967.

7. Hall, P. A., Levison, D. A., Woods, A. L., Yu, G. G.-W. Kellock, D. B., Watkins, J. A., Barnes, D. M., Gillett, C. E., Camplejohn, R., Dover, R., Wassem, N. H. and Lane, D. P.: Proliferating cell nuclear antigen (PCNA) immunolocalization in paraffin sections: an index of cell proliferation with evidence of deregulated expression in some neoplasms. J. Pathol. 162; 285-294, 1990.

8. Holmes, E. J.: Neoplastic Paneth cells Their occurrence in 2 adenomas and one carcinoma of the colon. Cancer 18; 1416-1422, 1965.

9. Ioachim, N. J., Delaney, W. E. and Madrazo, A.: Villous adenoma of the colon and rectum. An ultrastructural study. Cancer 34; 586-596, 1974.

10. Iwashita, A., Watanabe, H. and Enjoji, M.: Argyrophil and argentaffin cells in adenomas of the colon and rectum. Fukuoka Acta Med. 80; 114-124, 1989.

11. Katsuyama, T., Ono, K., Nakayama, J., Akamatsu, T. and Honda, T.: Mucosubstance histochemistry of the normal mucosa and carcinoma of the large intestine. Galactose oxidase-Schiff reaction and lectin stainings. Acta. Pathol. Jpn. 35; 1409-1425, 1985.

12. Katsuyama, T., Ono, K., Nakayama, J. and Kanai, M.: Recent advances in mucosubstance histochemistry. In "Gastric Mucus and Mucus Secreting Cells", ed. by K. Kawai, Excerpta Medica, Amsterdam, 1985, pp. 3-18.

13. Kurki, P., Ogata, K. and Tan, E. M.: Monoclonal antibodies to proliferating cell nuclear antigen (PCNA)/cyclin as probes for proliferating cells by immunofluorescence microscopy and flow cytometry. J. Immunol. Methods 109; 49-59, 1988.

14. Lewin, K.: Neoplastic Paneth cells. J. Clin. Pathol. 21; 476-479; 1968.

15. Mason, D. Y. and Taylor, C. R.: The distribution of meuramidase (lysozyme) in human tissues. J. Clin. Pathol. 28; 124-132, 1975.

16. Mathan, M., Hughes, J. and Whitehead, R.: The morphogenesis of the human Paneth cell. An immunocytochemical ultrastructural study. Histochemistry 87; 91-96, 1987.

17. Matsuzawa, K., Akamatsu, T. and Katsuyama, T.: 
Mucin histochemistry of pancreatic duct cell carcinoma, with special reference to organoid differentiation simulating gastric phloric mucosa. Hum. Pathol. 1992 23: 925-933, 1992.

18. Miyachi, K., Fritzler, M. J. and Tan, E. M.: Autoantibodies to a Nuclear antigen in proliferating cells. J. Immunol. 121; 2228-2234, 1978.

19. Montero, C. and Erlandsen, S. L.: Immunocytochemical and histochemical studies on intestinal epithelial cells producing both lysozyme and mucosubstance. Anat. Rec. 190; 127-142, 1978.

20. Morson, B. C.: Histological Typing of Intestinal Tumours. International Histological Classification of Tumours, No 15. WHO, Genova, 1976.

21. Nakayama, J., Ota, M., Honda, T. and Katsuyama, T.: Histochemical demonstration of sugar residues by lectin and immunocytochemical techniques for blood group antigens in human colon. Histochem. J. 19; 454$464,1987$.

22. Ono, K. and Katsuyama, T.: Mucosubstance histochemistry of the normal and epithelial neoplasms of the large intestine. Acta. Pathol. Jpn. 35; 281-297, 1985.

23. Ota, H., Nakayama, J., Katsuyama, T. and Kanai, M.: Histochemical comparison of specificity of three bowel carcinoma-reactive lectins, Griffonia Simplicifolia agglutininII, peanut agglutinin and Ulex Europaeus agglutinin-I. Acta. Pathol. Jpn. 38; 1547-1559, 1988.

24. Robbins, B. A., de la Vega, D., Ogata, K., Tan, E. M. and Nakamura, R. M.: Immunohistochemical detection of proliferating cell nuclear antigen in solid human malignancies. Arch. Pathol. Lab. Med. 111; 841-845, 1987.

25. Ruggiero, F., Cooper, H. S. and Steplewski, Z.: Immunohistochemical study of colorectal adenomas with monoclonal antibodies against blood group antigens (sialosyl Le ${ }^{\mathrm{a}}, \mathrm{Le}^{\mathrm{a}}, \mathrm{Le}^{\mathrm{b}}, \mathrm{Le}^{\mathrm{x}}, \mathrm{Le}^{\mathrm{y}}, \mathrm{A}, \mathrm{B}$, and $\mathrm{H}$ ). Lab. Invest. 59; 96-103, 1988.

26. Spicer, S. S.: Diamine methods for differentiating mucopolysaccharides histochemistry. J. Histochem. Cytochem. 13; 211-234, 1965.

27. Subbuswamy, S. G.: Paneth cells and goblet cells. J. Pathol. 111; 181-189, 1973.

28. Sunderland, D. A. and Binkley, G. E.: Papillary adenoma of the large intestine. A clinical and morphological study of forty-eight cases. Cancer 1; 184-207, 1948.

29. Tatematsu, M., Ichinose, M., Miki, K., Hasegawa, R., Kato, T. and Ito, N.: Gastric and intestinal phenotypic expression of human stomach cancers as revealed by pepsinogen immunohistochemistry and mucin histochemistry. Acta. Pathol. Jpn. 40; 494-504, 1990.

30. Von Dierendonck, J. H., Wijsman, J. H., Keijzer, R., von de Velde, C. J. H. and Cornelisse, C. J.: Cell-cyclerelated staining patterns of anti-proliferating cell nuclear antigen monoclonal natibodies. Am. J. Pathol. 138; 11651172, 1991.

31. Wiebecke, B., Brandts, A. and Eder, M.: Epithelial proliferation and morphogenesis of hyperplastic adenomatous and villous polyps of the human colon. Virchows Arch. (Pathol. Anat.) 364; 35-49, 1974. 